\title{
CAPÍTULO 15: PERFIL DE INVESTIGAÇÃO DA COMPOSIÇÃO MINERAL E CENTESIMAL DE AMOSTRAS DE ALIMENTOS DE CULTIVO CONVENCIONAL E AGROECOLÓGICO
}

\author{
CHAPTER 15: INVESTIGATION PROFILE OF THE MINERAL AND \\ CENTESIMAL COMPOSITION OF CONVENTIONAL AND AGROECOLOGICAL \\ AGRICULTURAL SAMPLES
}

\author{
Edna Santana de Sena ${ }^{1}$; Liz Oliveira dos Santos ${ }^{2}$
}

\begin{abstract}
Resumo
A avaliação da composição centesimal e mineral de amostras de alimentos são os métodos mais atualizados na modernidade para a extração e quantificação dos componentes orgânicos e minerais de um determinado alimento, com vistas a saber o seu valor nutricional e, consequentemente, a determinação da segurança alimentar para o consumidor. Diante disso, buscamos com o presente trabalho avaliar o perfil dos trabalhos publicados na base de dados do Google Scholar, envolvendo avaliação da composição centesimal e mineral em alimentos de origem animal, vegetal ou industrial, nos estados físicos comercializados no país (sólido e líquido) entre os anos de 2000 a 2020 no Brasil. Para isto, buscamos descrever e caracterizar a agricultura convencional e a agroecologia, com vistas a entender as fontes de alimentos mais presentes na sociedade. Por fim, buscarmos descrever os achados sob um olhar matemático com a linearização dos dados com a utilização da técnica dos mínimos quadrados.
\end{abstract}

Palavras-Chaves: Bromatologia; Centesimal; Mineral; Alimentos; Agricultura.

\begin{abstract}
The evaluation of the centesimal and mineral composition of food samples are the most updated methods in modern times for the extraction and quantification of the organic and mineral components of a given food, with a view to knowing its nutritional value and, consequently, the determination of food security. for the consumer. Therefore, we seek with the present work to evaluate the profile of the works published in the Google Scholar database, involving evaluation of the centesimal and mineral composition in foods of animal, vegetable or industrial origin, in the physical states marketed in the country (solid and liquid) between the years 2000 to 2020 in Brazil. For this, we seek to describe and characterize conventional agriculture and agroecology, with a view to understanding the food sources most present in society. Finally, we seek to describe the findings from a mathematical perspective with the linearization of the data using the least squares technique.
\end{abstract}

Keywords: Bromatology; Centesimal; Mineral; Foods; Agriculture.

\section{Introdução}

Nos últimos anos, grandes mudanças ocorreram nos hábitos alimentares da população, principalmente em relação à substituição de alimentos caseiros e naturais por alimentos industrializados, sendo estes responsáveis por $85 \%$ do consumo total de alimentos em 2007 (IBGE, 2008). E, de certo, a indústria vem participando desse novo direcionamento alimentar,

\footnotetext{
${ }^{1}$ Tecnologia em Alimentos, Universidade Federal do Recôncavo da Bahia, edna_sena95@yahoo.com

${ }^{2}$ Doutora, Universidade Federal do Recôncavo da Bahia, liz@ufrb.edu.br
} 
dado que a mesma congrega dezenas de milhares de estabelecimentos de micro e pequeno porte, distribuídos regionalmente, com grande contribuição na geração de empregos e tributos, além de ter forte potencial para o empreendedorismo como instrumento de inclusão social (MADI et al., 2015).

Além disso, é importante mostrar que a indústria de alimentos e bebidas é vital para o abastecimento da população nos centros urbanos, considerando-se toda a logística de armazenamento, distribuição e comercialização nos estabelecimentos atacadistas e varejistas (MADI et al., 2015). No entanto, a Revolução Industrial criou, entre outras coisas, a possibilidade de se comer mais e melhor trazendo novas formas de se produzir, transportar, cozinhar e comer. A partir daí, a indústria alimentícia possibilitou uma ampla produtividade (PELLERANO, 2014).

Diante disso, com o surgimento de um cenário que possibilita o desenvolvimento e comercialização de novos produtos, bem como o desenvolvimento de um pensamento ecológico com o passar dos tempos, há uma constante busca pelo desenvolvimento de técnicas que possibilitem uma análise para saber não apenas a composição alimentar, mas também a garantir a segurança do alimento. Com isso, como atualmente a análise mineral e a centesimal vem sendo empregada para saber da composição dos alimentos, principalmente industrializados, buscamos com o presente trabalho estudar o perfil da análise centesimal e mineral em alimentos de origem animal, vegetal ou industrial, nos estados físicos comercializados no país (sólido e líquido) entre os anos de 2000 e 2020 no Brasil.

\section{Agricultura convencional}

O início da agricultura está ligado a uma série de transformações no ato de produzir (ASSIS \& ROMEIRO, 2002). Nos últimos anos tem sido desenvolvida e incentivada uma agricultura baseada na conhecida "Revolução Verde", concretizada pelas práticas da mecanização, irrigação e fertilidade do solo, bem como o uso de agroquímicos no combate de pragas e doenças, intensificando assim a produção de alimentos (NEVES et al., 2004). Ela passou por várias revoluções agrícolas, que visavam diminuir as restrições do meio ambiente e necessidade de trabalho (ASSIS \& ROMEIRO, 2002).

Isso porque, como a agricultura moderna, a partir dos anos 50, priorizou um modelo tecnológico com base no uso intensivo da mecanização, adubos minerais de alta solubilidade e agrotóxicos (KAMIYAMA et al., 2011) houve a necessidade de um olhar moderno, mecanizado, utilizando técnicas sofisticadas, com uso de fertilizantes, sistemas de irrigação, 
correção dos solos para o plantio, uso de produtos químicos para corrigir as suas características, uso de estufas e seleção de sementes (FREITAS et al., 2014). Porém, este modelo teve início no século passado, quando a revolução industrial introduziu o uso de máquinas e equipamentos agrícolas (RICCI, ARAÚJO \& CASTRO, 2002).

Ela foi fortemente incentivada no Brasil na década de 70, e originou-se dos pacotes tecnológicos daquele governo, sendo sinônimo decrescimento econômico (CONTERATO \& FILLIPE, 2009). O modelo de agricultura praticado no período era direcionado aos grandes produtores e contribuiu tanto para o aumento da produção no meio rural como para a liberação de mão de obra e o crescimento das indústrias (MARIANI et al., 2015). Além disso, na atualidade, o sistema convencional é um dos sistemas de produção agrícola no país, cujo processo de produção está baseado no emprego de adubos químicos e agrotóxicos.

\begin{abstract}
O sistema agroalimentar moderno baseou-se nos avanços tecnológicos e nas descobertas científicas da agricultura e da pecuária (como o uso de fertilizantes sintéticos, agrotóxicos e drogas veterinárias; o melhoramento genético, o confinamento animal; a mecanização); na grande escala de produção (local e global); na industrialização; na oferta de alimentos desconectada da sazonalidade; na distribuição e comercialização em grandes redes varejistas; na escolha disponível a todos que podem arcar com os preços dos alimentos; nas desigualdades nutricionais entre e dentro das sociedades; e nas repercussões socioambientais vinculadas ao modelo produtivo (BEARDSWORTH \& KEIL, 1997).
\end{abstract}

Os termos agricultura convencional, tradicional, moderna, contemporânea, química, industrial e outros, são utilizados para definir o modelo de agricultura predominante em todo o mundo (RICCI, ARAÚJO \& CASTRO, 2002). Ele pode ser definido como um estilo de produção em larga escala, com apoio de recursos tecnológicos que permitam ampla produção e vasta contenção de praga, além de incentivos a modificações genéticas. Todavia, o sistema convencional de agricultura convencional é considerado altamente dependente de insumos externos, como fertilizantes químicos e agrotóxicos (ADL et al., 2011). Diante disso, é considerada uma das principais poluidoras dos recursos hídricos, sendo a salinidade e a contaminação por nitrato os principais indicadores de poluição (DIAZ \& ROSENBERG, 2008). Segundo Ricci, Araújo \& Castro (2002),

\footnotetext{
Nesse contexto monofatorial, os diferentes aspectos da produção são vistos de forma isolada; por exemplo, o surgimento de uma determinada praga é sanado pelo seu extermínio via tratamento com agrotóxicos. O melhoramento genético é sempre orientado para potencializar elevadas produtividades, incluindo a incorporação de resistência a pragas e doenças específicas, por meio de cruzamentos direcionados. Técnicos e pesquisadores tendem à superespecialização, fazendo com que a agricultura convencional fundamente-se, cada vez mais, em tecnologias de produto (agrotóxicos e fertilizantes minerais de alta concentração e solubilidade, maquinaria e sementes híbridas)" [sic] (RICCI, ARAÚJO \& CASTRO, 2002).
} 
De acordo com Darolt et al. (2003), a técnica da agricultura convencional consiste na preparação do solo com aração, gradagem e abertura de sulco, seguida de processo de fertilização com uso de adubos químicos altamente solúveis, como ureia, super simples, cloreto de potássio, NPK e outros. Isso porque, segundo o autor, a utilização desses fertilizantes é uma forma de reposição de nutrientes essenciais ao desenvolvimento do que se deseja plantar, dado que a natureza levaria muito tempo para recuperá-los, dificultando assim o processo de cultivo em larga escala.

Não obstante os autores ainda mencionam que a fertilização e preparação do solo não são o bastante para um cultivo em larga escala, devido ao surgimento de pragas e doenças que podem prejudicar a lavoura. Em decorrência do fato, usam-se inseticidas, fungicidas e nematicidas na intenção de eliminar parasitas e manter a produção longe de pragas, além de conter invasores com uso de herbicidas. Todavia, para um cultivo em grandes dimensões utilizam-se espécie do tipo lisa e uma monocultura, como supramencionado, para facilitar a colheita haja vista a necessidade de apenas uma única técnica para colher.

Uma das vantagens é a produção em massa de apenas uma espécie, que facilita o cuidado durante as épocas, mas também é um tipo de agricultura que produz em grande quantidade e preços menores, se comparado com produtos cultivados por meio de outras técnicas agrícolas, como a agricultura orgânica (DAROLT et al., 2003). Além disso, para esse tipo de agricultura não há necessidade de certificações, porém existe a indispensabilidade de disponibilidade de vasta área de terra para o plantio.

Com base no contexto de que a agricultura convencional sempre se apresentou como uma ameaça à biodiversidade, e até mesmo ao futuro da produção agrícola (FREITAS et al, 2014). O uso intensivo dos recursos naturais tem promovido mudanças drásticas no comportamento dos atributos físicos do solo (FREITAS et al., 2014). E segundo a Agência Nacional de Vigilância Sanitária (ANVISA, 2012), o uso intensivo de agrotóxicos pode causar a degradação dos recursos naturais como, solo, água, flora e fauna, em alguns casos de forma irreversível, portanto insustentável, levando a desequilíbrios biológicos e ecológicos.

Atualmente, o Brasil é um dos maiores compradores de agrotóxicos do mundo, entretanto as intoxicações provocadas por estas substâncias têm aumentado tanto entre os trabalhadores rurais, por ficarem expostos diretamente a estes produtos, como entre pessoas que se contaminam por meio da ingestão de alimentos contaminados (PIGNATI, 2011). No entanto, segundo a ANVISA (2012),

o sistema de produção convencional não consegue estabelecer a sustentabilidade do ponto vista social, ecológico e econômico. No ponto de vista social, a população tem 
consumido alimentos com a dosagem de agrotóxicos acima do limite máximo autorizado e, além disso, com ingredientes ativos não autorizados, segundo as amostras analisadas por cultura nos anos de 2011 e 2012.

Infelizmente, a modernização no meio rural não se ajustou às condições da agricultura familiar, reduziu a necessidade da força de trabalho e, consequentemente, excluiu o agricultor familiar do processo produtivo, tornando-se incremento de desigualdades sociais e pobreza nos meios urbano e rural (AZEVEDO et al., 2011). Além disso, agricultura convencional destruiu a fertilidade do solo, tornou a lavoura quimicamente dependente. E em decorrência desses eventos é necessário um longo tempo de transição para o solo poder se recuperar de forma natural. No entanto, isso é algo que não está dentro das possibilidades do camponês, principalmente a camada mais pobre, porque a parcela de terra de que dispõe precisa ser completamente utilizada. Não há possibilidade de deixar a terra em pousio para recuperar-se (STOTZ, 2012).

\section{Agroecologia}

A Agroecologia surgiu, precisamente, de uma interação entre os produtores (que se rebelam frente à deterioração da natureza e da sociedade, que é provocada pelo modelo produtivo hegemônico) e os pesquisadores e professores mais comprometidos com a busca de estratégias sustentáveis de produção (SEVILLA, 2001). Ela é uma ciência desenvolvida a partir da década de 1970, como consequência de uma busca de suporte teórico para as diferentes correntes de agricultura alternativa que já vinham se desenvolvendo desde a década de 1920 (ASSIS et al., 2002).

De acordo com os autores, ela é uma resposta aos críticos destes movimentos por uma nova agricultura integrada ao meio ambiente, que os definiam como uma tentativa retrógrada de volta ao passado na agricultura. E possui como variantes a agricultura ecológica, a agricultura alternativa e a agricultura sustentável, entre outras, e vem sendo desenvolvida e aprimorada desde o surgimento dos demais sistemas agrícolas do século passado (NODARI et al., 2015).

Porém, com um olhar mais cultural, alguns consideram que agroecologia é terra, instrumento e alma da produção, onde se plantam novas sementes do saber e do conhecimento, onde enraíza o saber no ser e na terra; é onde se amalgamam saberes e conhecimentos, descrita ainda como ciências, tecnologias e práticas, artes e ofícios no forjamento de um novo paradigma produtivo (LEFF, 2002). Assim, podemos considerar ela como o paradigma emergente, 
substituto da agricultura industrial ou convencional, exatamente por incorporar elementos de síntese, unificadores, integradores (NODARI et al., 2015).

Diante disso, pode-se afirmar que a agroecologia é a fusão entre a "Empiria camponesa" e a "Teoria Agroecológica" que estabelece um desenvolvimento alternativo, notadamente um Desenvolvimento Rural Sustentável (SEVILLA, 2001). Isso em decorrência dela ser um corpo de conhecimentos científicos e populares resultante do esforço de pesquisadores e de agricultores que se recusaram a admitir a modernização industrial da agricultura como a única forma de manejar os recursos naturais em um mundo submetido à globalização do capital (MOREIRA et al., 2004).

E ao contrário do que muitos proferem, segundo Paduá (2001), a agroecologia é muito mais do que uma forma de gestão de recursos naturais, configurando-se como um novo modo de vida rural, capaz de conjugar valores, qualidade de vida, trabalho, renda, democracia, emancipação política, em um mesmo processo. É um dos sistemas agrícolas mais sustentáveis sob todos os aspectos e propõe-se a resgatar a dignidade humana dos agricultores que ao longo da história domesticaram plantas e animais e mantiveram grande parte da diversidade genética utilizada pela espécie humana (NODARI et al., 2015).

Logo, podemos dizer que é uma modalidade de cultivo com vistas a respeitar o limite de desgaste dos meios naturais, usufruindo delas sem causar maleficio passível de necessidade de recursos artificiais para correção do solo ou mesmo do ambiente natural. Isso porque,

\begin{abstract}
os métodos da Agroecologia mostraram o potencial de suas estratégias para desenvolver uma agricultura sustentável e altamente produtiva, baseada na capacidade fotossintetizadora dos recursos vegetais, na conservação dos solos, no manejo de processos ecológicos, nos cultivos múltiplos e em sua associação com espécies silvestres, no "metabolismo" entre processo de produção primária, transformação tecnológica e reciclagem ecológica de resíduos industriais (TOLEDO, 1989).
\end{abstract}

Esse modo de pensar o plantio, permite observar a realidade atual em que a agricultura convencional se insere. Demonstrando que a globalização, hoje, oferece comida de todos os países em todas as partes do mundo, junto com o Mc Donald's e a Coca-Cola, que homogeneízam o gosto dos cidadãos deste planeta (LEFF, 2002), criando uma cultura artificial com produtos prejudiciais à saúde humana e, consequentemente, cultivando de forma irracional e desenfreada, desencadeando um processo caótico na natureza e na própria sociedade, que busca meios artificiais para conter problemas decorrentes do uso excessivo de um bem natural.

\title{
Análise centesimal e mineral de alimentos
}

Quando se fala em análise, seja de qualquer tipo, subentende-se que haverá sempre 
avaliações de cunho quantitativo que concomitantemente se seguirá para uma análise qualitativa. Diante disso, vale mencionar que na análise química qualitativa, é verificada a presença ou não de substâncias de interesse, sem importar ao analista a massa ou concentração dele na amostra. Todavia, de acordo com o autor, na análise química quantitativa, é verificado o teor (massa/concentração) do componente que está sendo determinado; assim, uma análise química quantitativa sempre terá como resultado um valor numérico seguido de uma unidade de volume, de massa ou de concentração, enquanto que na avaliação qualitativa haverá apenas a positividade ou não de substância de interesse na amostra (SKOOG, 2006).

Esses tipos de avaliações são de grande valia, principalmente no setor alimentício, porque, de acordo com Brinques (2015), alimentos são formados por um conjunto de diferentes constituintes, que podem ser classificados em substâncias nutrientes ou não nutrientes, que são de interesse social, principalmente por ter estrita relação com a saúde da população e de cada indivíduo que o consome. Até porque, os alimentos funcionais possuem propriedades nutricionais básicas, consumidos em dietas convencionais, demonstram capacidade de regular funções corporais de forma a auxiliar na prevenção de doenças (SOUZA et al., 2003).

Para a população em geral, é de extrema importância o conhecimento da composição que cada alimento, tanto em termos nutricionais, quanto microbiológicos. Dessa forma, as orientações nutricionais se tornam mais palpáveis, além da possibilidade de promover a segurança alimentar e nutricional (NICHELLE, 2018). Diante disso, a Bromatologia busca estudar os componentes químicos, estruturalmente definidos, que compõem os alimentos, com foco nos componentes presentes em grande quantidade (componentes centesimais), cuja concentração seja maior que 1\%, por exemplo, água, proteínas, carboidratos, vitaminas e minerais (VASCONCELOS, 2016).

Em alguns casos mais específicos, faz-se necessária a determinação de componentes individuais nos alimentos como alguns metais (principalmente metais tóxicos como chumbo e mercúrio), açúcares (como a lactose), aminoácidos específicos (fenilalanina e lisina), aflatoxinas entre outros (BOLZAN, 2013). Isso porque, a composição centesimal dos alimentos consiste em reconhecer a disponibilidade dos alimentos e, dessa forma, conhecer as características físico-químicas deles e seus nutrientes (NICHELLE, 2018). Não obstante, de acordo com a referida autora, também demonstra a proporção dos nutrientes em um alimento, sendo cada nutriente expresso na sua proporção em relação a $100 \mathrm{~g}$ do produto.

Nichelle (2018), compreende os objetivos da composição centesimal, reconhecer a disponibilidade dos alimentos e as suas características físico-químicas, bem como a composição dos nutrientes e a importância da variedade e da diversidade de alimentos na dieta humana. No 
entanto, seu princípio é fornecer valor nutritivo e calórico dos alimentos, haja vista que de posse das análises é possível detectar se o alimento compreende os padrões previstos na legislação. Isso porque, em todo o mundo existem uma gama de alimentos que, nativos ou não, possuem grande importância socioeconômica e enorme potencial de exploração comercial (ROCHA et al., 2012), visto que o Brasil e outros países são detentores de uma vasta biodiversidade e grande extensão territorial (NICHELLE, 2018), destaca-se a importância da realização destas análises.

Consoante, as análises são necessárias para elaboração de programas de nutrição, saúde e educação, e a composição presente em cada alimento permite traçar estratégias nutricionais, principalmente, para contornar problemas decorrentes do excesso ou falta de determinadas substâncias orgânicas e inorgânicas no corpo humano, e até mesmo animal. Exemplo disso, de acordo com Bolzan (2013), é a análise centesimal dos açúcares em geral que estão diretamente atrelados ao desenvolvimento do diabetes, e a importância da análise é para auxiliar nas dietas. No entanto, estudos centesimais de metais pesados tem sua relevância por serem extremamente tóxicos, devendo ser evitados, e por permitir a detecção de existência de contaminação, seja por qualquer fator.

Existem diversos tipos de análises de interesse, seja de açúcares, lipídios, metais pesados, lactose, fenilalanina, lisina e várias outras (BOLZAN, 2013) que permitem o fornecimento de subsídios para o diagnóstico do estado de saúde e nutrição de uma população por meio da avaliação do consumo alimentar (NICHELLE, 2018), bem como para seu tratamento e prevenção de agravos, e é com base nesse teor de nutrientes que se dá a avaliação da dieta, permitindo decidir sobre sua adequação ou inadequação. Porém, no plano individual, o acompanhamento do padrão alimentar é um importante subsídio para o estabelecimento da situação de risco nutricional, determinado, de um lado, por carências específicas e, de outro, por práticas alimentares inadequadas (CECCHI, 2015).

Por outro lado, quando se pretende desenvolver um novo produto alimentício e lançálo no mercado, é fundamental submetê-lo a análises de composição centesimal (ROCHA et al., 2012). Com base nas análises de composição centesimal dos alimentos é que são elaboradas as tabelas de composição de alimentos, as quais são vastamente utilizadas em avaliações do consumo de alimentos de indivíduos (NICHELLE, 2018), e que possuem como referências as tabelas de composição de alimentos: a) Tabela Brasileira de Composição de Alimentos (TACO) — 2011; b) Tabela Sonia Tucunduva Philippi — 2013; c) Tabela Instituto Brasileiro de Geografia e Estatística (IBGE) - 2008-2009; d) Tabela de composição química de alimentos (Guilherme Franco).

Por convenção, segundo Nichelle (2018) os grupos homogêneos de substâncias que 
constituem os alimentos são: a) Umidade ou voláteis a $105^{\circ} \mathrm{C}$; b) Cinzas ou resíduo mineral fixo (RMF); c) Lipídeo, gorduras ou extrato etéreo; d) Proteína bruta ou extrato nitrogenado; e) Carboidratos, glicídios, açúcares ou sacarídeos; e f) Fibras ou substâncias insolúveis. Contudo, vale mencionar que informações sobre a composição centesimal de alguns fitoterápicos são escassas e, muitas vezes, eles são utilizados pela população de modo empírico, sem nenhuma identificação dos constituintes que possam estar envolvidos na eficácia terapêutica (ROCHA et al., 2012).

Entretanto, a composição centesimal não busca analisar apenas as substâncias orgânicas existentes nos alimentos. Elas também podem analisar as características minerais presentes neles, que se referem as substâncias inorgânicas existentes em todos os alimentos, em menor quantidade, mas que exercem a função de constituintes no nosso organismo e são indispensáveis ao processo vital, devendo estar presentes nos alimentos em proporções adequadas. Isso porque, segundo o autor, eles são responsáveis pelo equilíbrio osmótico dos líquidos do organismo e agem na manutenção do equilíbrio acidobásico por assumirem a função do ácido ou das bases, dependendo do alimento, além de serem os responsáveis por dar rigidez aos ossos e dentes (VASCONCELOS, 2016).

\section{Material e Métodos}

O presente trabalho buscou realizar uma revisão de literatura acerca da realização de análise centesimal e mineral em alimentos brasileiros, publicados no Google Scholar, entre os anos de 2000 e 2020, com a utilização dos descritores: "alimentos e bromatologia", "alimentos e centesimal", "composição mineral de alimentos" e "Brasil". Obtendo como resultado 1980 trabalhos relacionados. Porém, para utilização neste estudo, foi realizada uma busca de forma aleatória, sendo selecionado 120 artigos científicos publicados em anais brasileiros no período supramencionado, o que equivale a $6,25 \%$.

Com os achados selecionados extraíram-se as informações como: ano de publicação, caracterização do estado físico do alimento estudado pelo texto (se sólido ou se líquido) e origem do alimento (se de origem animal, vegetal ou se ele é industrializado). E, entendendo por alimento industrializado todo aquele que tenha passado por algum processo de transformação que retirou as características básicas e, assim, transformando-o num produto comercial.

As informações obtidas foram dispostas em forma de rol, com caracterização dos dados por ano. Para, a partir de então, serem construídos gráficos que possam promover percepção da 
tendência desse tipo de análise. Não obstante, com os dados dispostos em gráficos e tabelas, buscou-se utilizar a técnica dos mínimos quadrados na tentativa de obter uma equação linear que proporcionasse um entendimento matemático mais apurado sobre o comportamento deste tipo de análise na atualidade brasileira

\section{Resultados e Discussão}

Dos 120 artigos encontrados no Google Scholar, 89,17\% (107/120) se referiram a estudos relacionados a alimentos do tipo sólido, enquanto 10,83\% (13/120) se referem a alimentos líquidos. No entanto, desses artigos 27 se relacionavam a alimentos de origem animal, 45 a alimentos de origem vegetal e 50 relativos a alimentos do tipo industrializado, correspondendo ao percentual de 22,5\%,37,5\% e 41,67\% respectivamente. Contudo, 2 (1,67\%) deles apresentaram estudos simultâneos de alimentos com características distintas ou mesmo de origens distintas.

Os estudos sobre alimentos industrializados obtiveram maior preferências entre os autores consultados, ficando, assim, em primeiro lugar no interesse dos atuais pesquisadores. Ficando os alimentos vegetais em segundo lugar de interesse e os de origem animal em último lugar. Todavia, cabe salientar que como o estudo observou uma amostra de 6,06\% (120 artigos) dentre todos artigos os disponibilizados no site de busca, deve-se entender que pode haver oscilações no entendimento do tipo de alimento possui maior interesse de estudo de análise centesimal e mineral, fazendo com que os alimentos vegetais e animais possam ganhar maior destaque frente aos alimentos industrializados.

Porém, frente aos dados analisados, pode-se notar que há uma tendência de crescimento do interesse pelos produtos industrializados em comparação com os outros, mas não significam que não haja estudos sobre alimentos de origem animal ou vegetal no decorrer dos anos. Isso porque, de acordo com os dados, existe um crescimento ano a ano de estudos relativos a alimentos industrializados, mesmo que estes ainda possuam oscilações de dados. Porém, o número de estudos da amostra apresentou um pico de 9,1\% (11 estudos) de interesse no ano de 2017.

Com a linearização dos dados, pudemos obter a equação linear para alimentos de origem animal y $=0,0727 x-144,9$ (com medida de ajuste $R^{2}=0,144$ ); equação linear para alimentos de origem industrial $y=0,3078 x-616,28$ (com medida de ajuste $R^{2}=0,4708$ ); e equação linear para alimentos de origem vegetal $y=0,0273 x-52,675$ (com medida de ajuste $\mathrm{R}^{2}=0,0109$ ), sendo o $\mathrm{R}^{2}$ uma medida de ajuste relativa a regressão linear (linearização) generalizada feita com os dados extraídos dos artigos. 
Observando os coeficientes angulares das equações lineares obtidas (0,0273 para origem vegetal; 0,0727 para origem animal; e 0,3078 para origem industrial), pode-se notar que eles representam a rapidez média de crescimento do interesse por esses tipos de produtos no decorrer dos tempos (TIPLER, 2011). E, por mais que haja oscilações, existe indícios de uma tendência de crescimento como demonstrado pelas equações citadas e descritas nas Figuras 2 , 4 e 5. Não obstante, pode-se observar que o interesse prevalece pelos industrializados, que apresenta uma velocidade 4,2 vezes maior que o interesse por produtos de origem animal e 11,2 vezes maior que produtos de origem vegetal.

Ao avaliar a realidade brasileira atual e os artigos selecionados para extração de dados para o presente estudo de revisão em amostra, tem-se o desenvolvimento de novos produtos apresentados ao mercado provenientes de utilização da matéria orgânica geralmente descartada no consumo de alimentos vegetais, o que eram considerados agroresíduos, como a casca de banana, talos e outros componentes vegetais de variados tipos de alimentos do gênero; bem como novas tendências de desenvolvimentos de produtos com vistas a suplementar dietas nutritivas para indivíduos acometidos por alguma doença e até mesmo saudáveis, como farinha de abóbora, farinha de banana, farinha de linhaça e dentre outros.

Além disso, é possível notar que os avanços na agricultura promoveram o desenvolvimento de diversos tipos de alimentos não cultiváveis em determinadas localidades, o que proporcionou uma melhora na disponibilidade de alimentos em determinadas regiões. Porém, não apenas isso se vê uma tentativa de valorização de produtos ou mesmo subprodutos provenientes de recursos vegetais, como produção de geleias a partir da goiaba, da banana ou mesmo de maçã, além de farinhas e outros recursos alimentares disponibilizados para alimentação de diversos tipos de animais.

Não obstante, em virtude da disponibilização de novos produtos no mercado, existe a necessidade, de acordo com as normas brasileiras (mencionadas em seção anterior), de estudo sobre a composição nutricional desses alimentos para determinar a segurança de seu consumo. Entretanto, esses novos produtos demonstram uma corrida por alimentos nutritivos, provenientes de baixa manipulação industrial, que sirvam como solução para a contenção do desenvolvimento de doenças crônicas na população, principalmente por excesso de açúcar e sal em alimentos industrializados. Mas que, sem esquecer, os estudos de composição centesimal e mineral de alimentos servem como proposito não apenas para determinação da segurança alimentar, mas para informar à população que o consome sobre sua composição. 
Figura 1. Disposição dos dados segundo a origem alimentar.

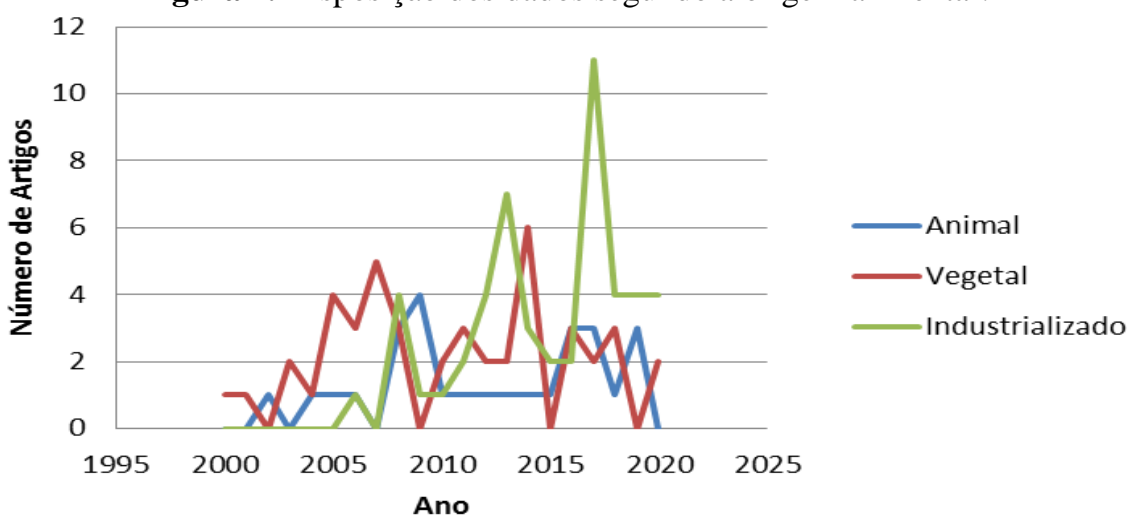

Fonte: Própria (2020).

Figura 2. Linearização dos dados relativos à origem alimentar proveniente de animal.

Animal

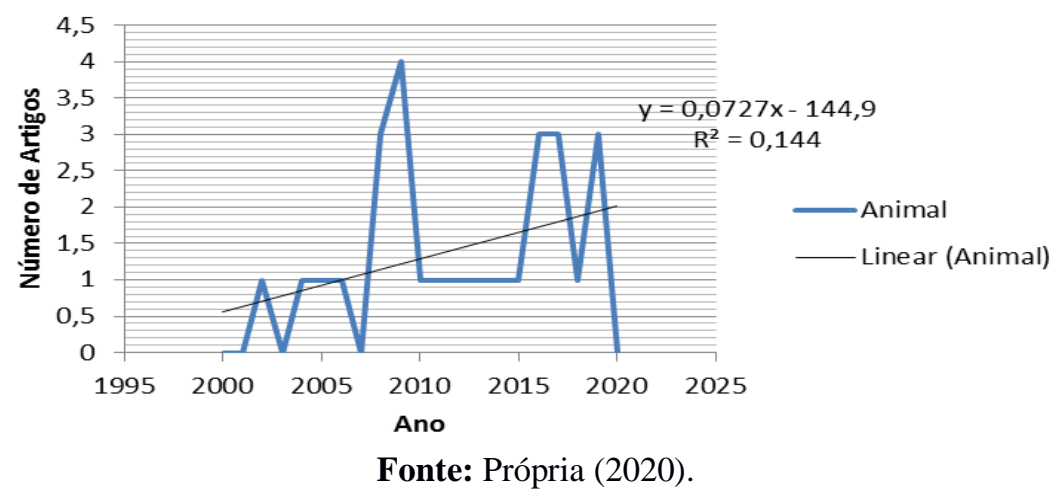

Figura 3. Disposição dos dados segundo estado físico do alimento.

Industrializado

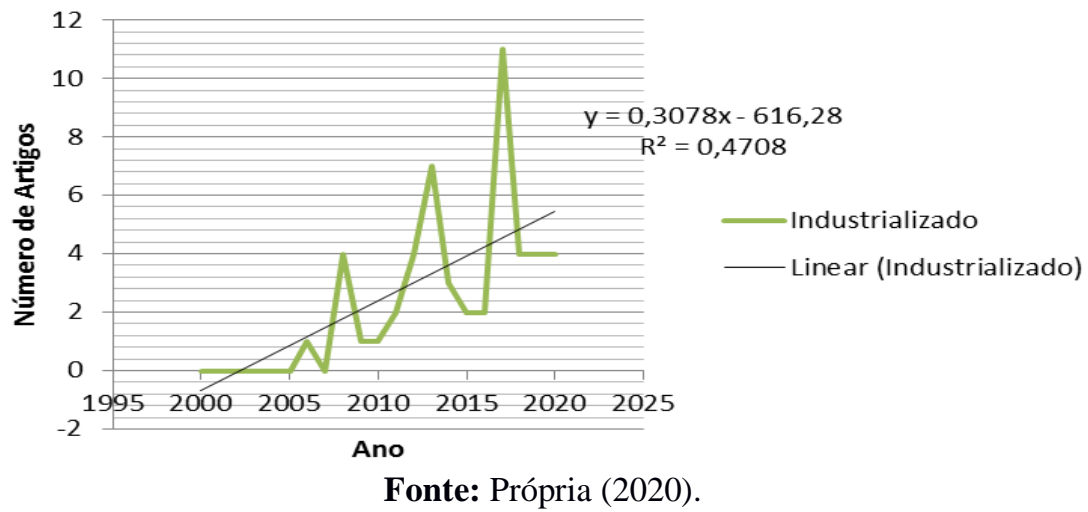

[222] 
Figura 4. Linearização dos dados relativos à origem alimentar proveniente de industrializados.

\section{Vegetal}

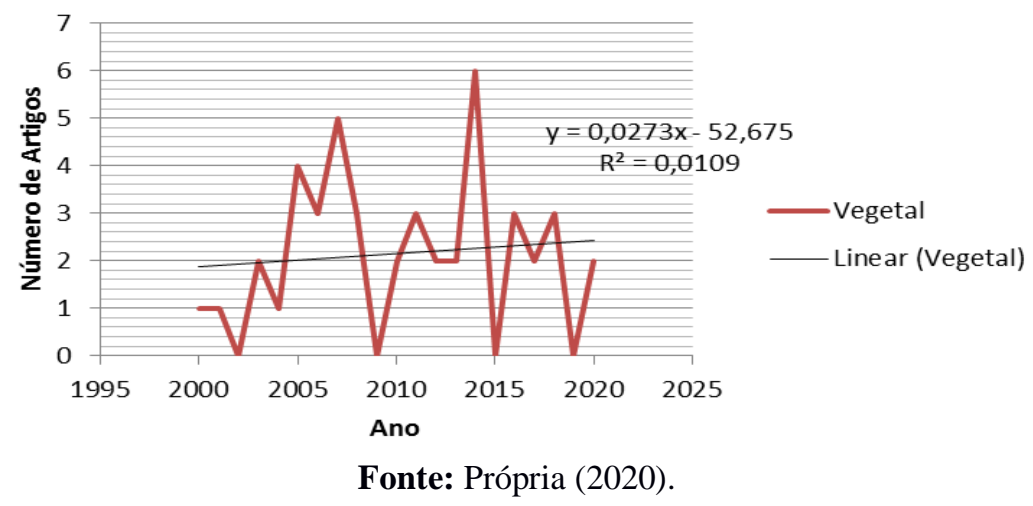

Figura 5. Linearização dos dados relativos à origem alimentar proveniente de vegetal.

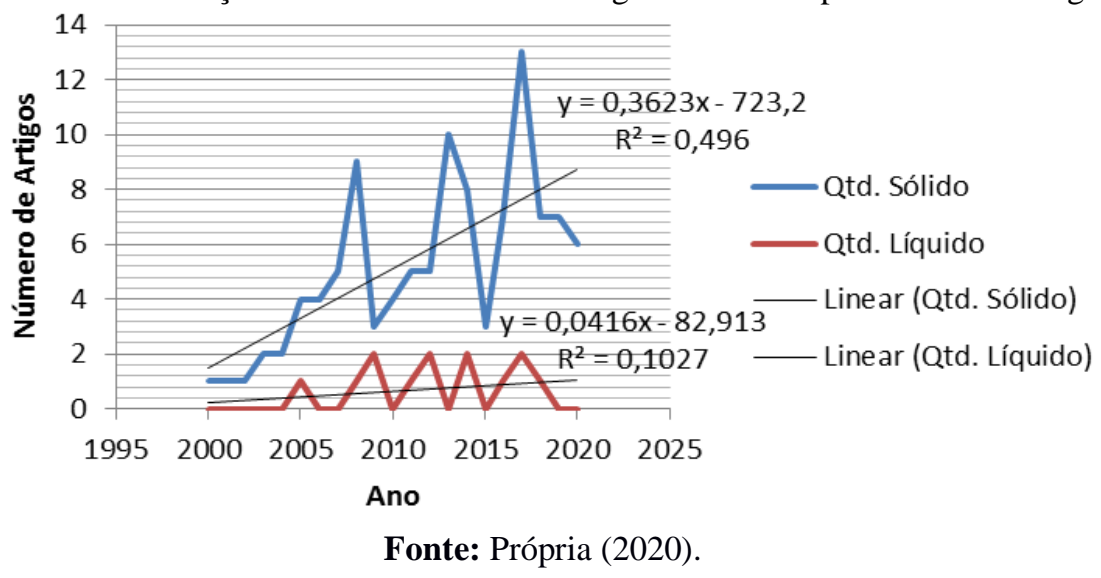

Diante disso, pode-se dizer que entre os anos de 2010 a 2020, o crescimento dos produtos advindos de alimentos típicos e exóticos (o que confere uma ideia de exclusividade a depender do tipo de acesso que se tem a esse novo tipo de alimento disponibilizado no mercado, promovendo até mesmo a ideia de status) vem crescendo e são objetos de estudos pelos diversos pesquisadores na área de alimentos. Porém, conforme a Figura 3, pode-ses observar que o estudo sobre alimentos em estado sólido é superior aos estudos de alimentos líquidos.

Esse fato pode evidenciar que a produção de alimentos em estado sólido é o mais preferido para ser consumido por toda a sociedade ou, ainda, que os alimentos em estado líquido são de menor interesse para estes tipos de estudos, seja por existirem em menor quantidade quando comparado aos alimentos sólidos, seja por baixo interesse industrial para desenvolvimento de novos alimentos nesse estado físico. Todavia, como pode-se notar pela linearização dos dados o crescimento de estudos relacionados a alimentos em estado sólido vem crescendo com uma rapidez de 8,7 vezes se comparado com os alimentos em estado líquido.

A equação linear $y=0,3623 x-723,2$ representa o crescimento de estudos em torno dos alimentos sólidos, de todos os tipos de origem, e que possui uma variação estatística para o modelo apresentado de $\mathrm{R}^{2}=0,496$; enquanto a equação linear $\mathrm{y}=0,0416 \mathrm{x}-82,913$ descreve $\mathrm{o}$ 
comportamento de estudos relacionados a alimentos líquidos, também provenientes de qualquer tipo de origem, e possuindo uma oscilação estatística para o modelo apresentado em torno de $\mathrm{R}^{2}=0,1027$. Infelizmente, com os dados, nota-se que os alimentos em estado líquido são de menor interesse, porém são os de maior propensão e facilidade para ocorrência de fraudes e adulterações. Ou, ainda, os alimentos líquidos são menos lançados no mercado em comparação com sólidos.

\section{Conclusões}

Ante o exposto, pode-se dizer que nos últimos anos, entre 2000 e 2020, o crescimento dos produtos advindos de alimentos típicos e exóticos vem crescendo - o que conferem uma ideia de exclusividade a depender do tipo de acesso que se tem a esse novo tipo de alimento disponibilizado no mercado (promovendo até mesmo a ideia de status) - e são objetos de estudos pelos diversos pesquisados na área de alimentos para produzir dados que informem as composições nutricionais, a comprovação da segurança alimentar, do alimento.

Ainda, que os produtos industrializados, mesmo que minimamente, vem crescendo no Brasil e vem ganhando cada vez mais atenção no meio científico porque estão também ganhando os olhares da população. Além do mais, é notado há ainda uma quantidade de trabalhos envolvendo avaliação da composição centesimal e mineral de matrizes alimentares com cultivo de origem orgânica é pequeno, podendo ser considerada uma área promissora para o desenvolvendo de novas pesquisas.

\section{Referências}

ADL, S.; IRON, D.; KOLOKOLNIKOV, T. A threshold area ratio of organic to conventional agriculture causes recurrent pathogen outbreaks in organic agriculture. Science of the Total Environment, Amsterdam, v.409, p.2192-2197, 2011.

ASSIS, R.L.; ROMEIRO, A.R. Agroecologia e agricultura orgânica: controvérsias e tendências. Desenvolvimento e Meio Ambiente, Curitiba, n.6, p.67-80, 2002.

ASSIS. R. L.; ROMEIRO, A. R. Agroecologia e agricultura orgânica: controvérsias e tendências. Desenvolvimento e Meio Ambiente, n. 6, p. 67-80, jul./dez. 2002. Editora UFPR.

AZEVEDO, Elaine de; PELICIONI, M. C. F. Promoção da Saúde, Sustentabilidade e Agroecologia: uma discussão intersetorial1 Health Promotion, Sustainability and Agroecology: an intersectoral discussion. Saúde Soc. São Paulo, v.20, n.3, p.715-729, 2011

BEARDSWORTH, A.; KEIL, T. Sociology on the menu. London: Routdedge, 1997. 
BOLZAN, Rodrigo Cordeiro. Bromatologia. - Frederico Westphalen: Universidade Federal de Santa Maria, Colégio Agrícola de Frederico Westphalen, 2013.

CONTERATO, M. A. e FILIPI, E. E. Teorias do Desenvolvimento. SEAD. Editora UFRGS. 2009.

CECCHI, H. M. Fundamentos teóricos e práticos em análise de alimentos. 2. ed. Campinas: Unicamp, 2015.

DAROLT, Moacir; RODRIGUES, Anibal; NAZARENO, Nilceu; BRISOLLA, Airton; RUPPEL, Osvaldo. Análise comparativa entre o sistema orgânico e convencional de batata comum. Disponível em: < https://www.researchgate.net/profile/Nilceu_Nazareno/publication/266461261_ANALISE_C OMPARATIVA_ENTRE_O_SISTEMA_ORGANICO_E_CONVENCIONAL_DE_BATAT A_COMUM/links/55d1ecbb08ae95c3504d626c/ANALISE-COMPARATIVA-ENTRE-OSISTEMA-ORGANICO-E-CONVENCIONAL-DE-BATATA-COMUM.pdf > . Acesso em: 24 de Julho de 2020.

DIAZ, R.J.; ROSENBERG, R. Spreading dead zones and consequences for marine ecosystems. Science, Nova York, v.321, p.926-929, 2008.

FREITAS, Janierk Pereira de; MEDEIROS, Monalisa Cristina Silva; SILVA, José Adailton Lima; Freitas, Francisco Eduardo de; NETO, Manoel Ferreira da Silva. Agroecologia como alternativa para mudanças de um estilo de agricultura convencional para uma agricultura de base familiar: o caso do assentamento Santo Antônio no município de cajazeiras-pb. CAMPO-TERRITÓRIO: revista de geografia agrária, v. 9, n. 17, p. 436-468, abr., 2014.

KAMIYAMA, A.; MARIA, I.C.; SOUZA, D.C.C.; SILVEIRA, A.P.D. Percepção ambiental dos produtores e qualidade do solo em propriedades orgânicas e convencionais. Bragantia, Campinas, v.70, n.1, p.176-184, 2011.

LEFF, Enrique. Agroecologia e saber ambiental. Agroecol.e Desenv. Rur. Sustent., Porto Alegre, v.3, n.1, jan./mar.2002.

MARIANI, C. M.; HENKES, J. A. Agricultura orgânica x agricultura convencional soluções para minimizar o uso de insumos industrializados. R. gest. sust. ambient., Florianópolis, v. 3, n. 2, p. 315-338, out. 2014/mar. 2015.

MOREIRA, R. M.; CARMO, M. S. Agroecologia na construção do desenvolvimento rural sustentável. Agric. São Paulo, São Paulo, v. 51, n. 2, p. 37-56, jul./dez. 2004.

NEVES, M. C. P. et al. Agricultura Orgânica: uma estratégia para o desenvolvimento de sistemas agrícolas sustentáveis. Rio de Janeiro: EDUR, 2004.

NICHELLE, Pryscila Gharib. Bromatologia. - Porto Alegre: SAGAH, 2018.

NODARI, R. O.; GUERRA, M. P. A agroecologia: estratégias de pesquisa e valores.

Estudos avançados 29 (83), 2015. 
PADUA, J. A. (Org.) Seminário preparatório ao Encontro Nacional de Agroecologia. Rio de Janeiro, 27 e 28 de julho de 2001. Rio de Janeiro, agosto de 2001.

PIGNATI, W. Não existe uso seguro de agrotóxicos. Disponível

em:<http://www.ihu.unisinos.br/entrevistas/44972-nao-existe-uso-seguro-de-agrotoxicosentrevista-especial-com-wanderlei-pignati >. Acesso em: 27 de junho de 2020.

RICCI, Marta dos Santos Freire; ARAÚJO, Maria do Carmo Fernandes; CASTRO, Cristina Maria de. Cultivo orgânico do café: recomendações técnicas - Brasília: Embrapa Informação Tecnológica, 2002.

ROCHA, Denise Alvarenga; ABREU, Celeste Maria Patto De; SOUSA, Raimundo Vicente De; CORRÊA, Angelita Duarte. Método de obtenção e análise da composição centesimal do polvilho da fruta-de -lobo. Rev. Bras. Frutic., Jaboticabal - SP, v. 34, n. 1, p. 248-254, março 2012.

SEAB/DERAL. Preços Médios Mensais Recebidos pelos Produtores. Disponível em: <http://www.pr.gov.br/seab/deral>. Acesso em: 23 de Julho de 2020.

SEVILLA, E. Agroecología y desarrollo rural sustentable: una propuesta desde Latinoamérica (mimeo). In: SARANDON, Santiago (Ed.) Agroecología: el camino para una agricultura sustentable. Rosario, 2000.

STOTZ, E. N. Os limites da agricultura convencional e as razões de sua persistência: estudo do caso de Sumidouro, RJ. Rev. bras. Saúde ocup., São Paulo, 37 (125): 114-126, 2012.

TOLEDO, V.M. et al. La producción rural en México: alternativas ecológicas. México: Fundación Universo Veintiuno, 1989.

VASCONCELOS, V. G. Bromatologia. São Paulo: Pearson Education do Brasil, 2016. 